\title{
Zerwürfnis
}

\section{AOK-Vorstände treten zurück}

In einer knappen Pressemitteilung gab der AOK-Bundesverband Anfang Juli den Rücktritt der beiden geschäftsführenden Vorstände, Jürgen Graalmann und Uwe Deh, bekannt. Grund seien unterschiedliche Auffassungen über die künftige Aufstellung, Ausrichtung und Weiterentwicklung des Verbandes, teilte die AOK mit. Tatsächlich ging dem Schritt nach Informationen des Berliner Tagesspiegel ein monatelanger Machtkampf zwischen den beiden Spitzenfunktionären voraus. Querelen mit den regionalen Kassen, die den Einfluss des Bundesverbandes beschneiden wollen, kamen hinzu. Auch der Wechsel des Chefs der AOK-Grundsatzabteilung, Jan Carels, zum Verband der forschenden Pharma-Unternehmen (vfa) dokumentiert die Probleme der Verbandsspitze.

Graalmann kam Anfang 2009 zum AOK-Bundesverband, im Oktober 2011 wurde er Vorsitzender. Zuvor war er unter ande- rem als Vorstandsreferent bei der Barmer Ersatzkasse tätig. Der gebürtige Ostfriese gilt als innovationsfreudig und ist gern gesehener Gast gesundheitspolitischer Diskussionsrunden. Er hat der etwas behäbig geltenden AOK einen jugendlicheren Anstrich gegeben. Deh wechselte im Oktober 2011 von der Spitze der AOK Sachsen-Anhalt in den Vorstand des Bundesverbandes und kümmerte sich dort vor allem um die Finanzen und die Krankenhausversorgung. Bis zur nächsten Vorstandswahl übernehmen die Chefs der AOKen Nord-West und Nord-Ost, Martin Litsch und Frank Michalak, die Aufgaben an der Spitze von Deutschlands größtem Krankenkassenverbund.

Der AOK-Bundesverband ist die Dachorganisation von elf selbstständigen Ortskrankenkassen, bei denen rund 24 Millionen Menschen versichert sind.

\section{Gesetzliche Krankenversicherung Immer weniger Kassen}

Die Zahl der gesetzlichen Krankenkassen ist in den vergangenen 25 Jahren deutlich zurückgegangen. Gab es laut GKV-Mitgliederstatistik 1990 in Deutschland noch 1147 gesetzliche Kassen, so verringerte sich deren Zahl bis 2015 auf 124. Zu diesem Rückgang kam es vor allem durch Fusionen und in Einzelfällen durch Insolvenz. Auch reduzierte sich die Zahl zum jüngsten Stichtag, dem 1. Januar 2015, durch die Schließung von einzelnen Krankenkassen, beispielsweise der BKK Dasa Airbus und City-BKK. Von den rund 70 Millionen gesetzlich Krankenversicherten (GKV-Mitgliedern) gehört der größte Anteil (44 Pro-

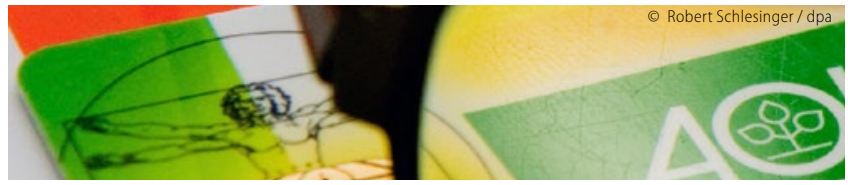

zent) zu den Pflichtversicherten. 25 Prozent sind Familienangehörige (Ehepartner, Kinder) beitragsfrei mitversichert. Die meisten Versicherten zählen die sechs Ersatzkassen mit rund 26,4 Millionen, gefolgt von den elf Ortskrankenkassen (AOK) mit rund 24,4 Millionen Versicherten. Die frühere Bundesgesundheitsministerin Ulla Schmidt (SPD) hielt vor vier Jahren langfristig eine Zahl von 30 bis 50 Krankenkassen für ausreichend. Berücksichtigt man, dass aktuell lediglich 64 Krankenkassen mehr als 50.000 Mitglieder zählen, ist der Trend zu mehr Großkrankenkassen bereits prinzipiell erreicht worden: Von den 90 kleineren Kassen mit weniger als 50.000 Mitgliedern sind 32 „geschlossene“ Betriebskrankenkassen. In dieser Größenklasse hat sich in den vergangenen zehn Jahren auch der größte Schwund an selbstständigen Kassen eingestellt. Die zahlenmäßig dominierenden Betriebskrankenkassen verzeichnen rund 11,7 Millionen Versicherte.

\section{BVA rügt Praktiken der Kassen}

Das Bundesversicherungsamt (BVA) sieht bei Beratungsleistungen und Bonusprogrammen der Krankenkassen erhebliche Mängel. Dies geht aus dem vor Kurzem veröffentlichten Tätigkeitsbericht 2014 hervor. Darin kritisiert das BVA, Kassen würden Beraterleistungen zunehmend an private Firmen auslagern und den Dienstleistern die Sozialdaten der Versicherten aushändigen. „Für diese Datenübermittlung und -verarbeitung besteht keine Rechtsgrundlage, wenn der Versicherte nicht zuvor in die Datenübermittlung eingewilligt hat und der Erstkontakt mit dem Versicherten durch die Krankenkasse erfolgt“, stellt das
BVA heraus. Weiterhin nahm das Amt die Angebote der Kassen kritisch unter die Lupe, bei denen Versicherte Bonusleistungen erhalten, wenn sie ihre Gesundheitsdaten über Fitness-Apps an die Krankenkasse übermitteln. Aus Sicht des BVA erlaube der Gesetzgeber grundsätzlich solche Maßnahmen, aber diese seien nur dann qualitätssichernd, wenn sie nachweisbar unter fachlicher Anleitung erfolgen. Das BVA sieht die über Apps übermittelten Gesundheitsdaten nicht mit der Vorgabe des Gesetzgebers in Einklang.

cas 